\title{
Article \\ Site-Specific Dual-Labeling of a VHH with a Chelator and a Photosensitizer for Nuclear Imaging and Targeted Photodynamic Therapy of EGFR-Positive Tumors
}

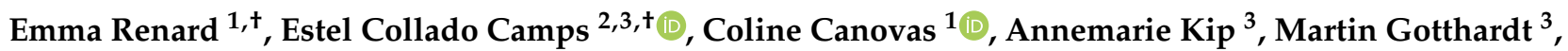 \\ Mark Rijpkema ${ }^{3}$, Franck Denat ${ }^{1}\left(\mathbb{D}\right.$, Victor Goncalves ${ }^{1}$ and Sanne A. M. van Lith ${ }^{3, *(D)}$ \\ 1 Institute de Chimie Moléculaire de l'Université de Bourgogne ICMUB UMR CNRS 6302, \\ Université Bourgogne Franche-Comté, 21000 Dijon, France; Emma_Renard@etu.u-bourgogne.fr (E.R.); \\ coline.canovas@gmail.com (C.C.); franck.denat@u-bourgogne.fr (F.D.); \\ victor.goncalves@u-bourgogne.fr (V.G.) \\ 2 Department of Biochemistry, Radboud Institute for Molecular Life Sciences, Radboudumc, \\ 6525 GA Nijmegen, The Netherlands; E.ColladoCamps@radboudumc.nl \\ 3 Department of Medical Imaging, Nuclear Medicine, Radboudumc, 6525 GA Nijmegen, The Netherlands; \\ Annemarie.Kip@radboudumc.nl (A.K.); Martin.Gotthardt@radboudumc.nl (M.G.); \\ Mark.Rijpkema@radboudumc.nl (M.R.) \\ * Correspondence: sanne.vanlith@radboudumc.nl \\ check for \\ updates
}

Citation: Renard, E.; Collado Camps, E.; Canovas, C.; Kip, A.; Gotthardt, M.; Rijpkema, M.; Denat, F.; Goncalves, V.; van Lith, S.A.M. Site-Specific Dual-Labeling of a VHH with a Chelator and a Photosensitizer for Nuclear Imaging and Targeted Photodynamic Therapy of EGFR-Positive Tumors. Cancers 2021, 13, 428. https://doi.org/10.3390/ cancers13030428

Academic Editors:

Vladimir Tolmachev, Max Witjes and Anzhelika Vorobyeva

Received: 21 December 2020

Accepted: 21 January 2021

Published: 23 January 2021

Publisher's Note: MDPI stays neutral with regard to jurisdictional claims in published maps and institutional affiliations.

Copyright: () 2021 by the authors. Licensee MDPI, Basel, Switzerland. This article is an open access article distributed under the terms and conditions of the Creative Commons Attribution (CC BY) license (https:// creativecommons.org/licenses/by/ $4.0 /)$.
Simple Summary: Variable domains of heavy chain only antibodies are small proteins that can be used for tumor imaging and therapy upon conjugation of functional groups. As frequently used random conjugation techniques can decrease binding to the target of interest, site-specific conjugation of these functional groups is preferred. Here, we optimized site-specific conjugation of both a chelator for binding of a radiometal and a photosensitizer to epidermal growth factor receptor (EGFR) binding VHH 7D12. We characterized this dual-labeled VHH for nuclear imaging and targeted photodynamic therapy of EGFR-expressing tumors.

Abstract: Variable domains of heavy chain only antibodies (VHHs) are valuable agents for application in tumor theranostics upon conjugation to both a diagnostic probe and a therapeutic compound. Here, we optimized site-specific conjugation of the chelator DTPA and the photosensitizer IRDye700DX to anti-epidermal growth factor receptor (EGFR) VHH 7D12, for applications in nuclear imaging and photodynamic therapy. 7D12 was site-specifically equipped with bimodal probe DTPA-tetrazine-IRDye700DX using the dichlorotetrazine conjugation platform. Binding, internalization and light-induced toxicity of DTPA-IRDye700DX-7D12 were determined using EGFRoverexpressing A431 cells. Finally, ex vivo biodistribution of DTPA-IRDye700DX-7D12 in A431 tumor-bearing mice was performed, and tumor homing was visualized with SPECT and fluorescence imaging. DTPA-IRDye700DX-7D12 was retrieved with a protein recovery of $43 \%$, and a degree of labeling of 0.56 . Spectral properties of the IRDye700DX were retained upon conjugation. ${ }^{111} \mathrm{In}$ labeled DTPA-IRDye700DX-7D12 bound specifically to A431 cells, and they were effectively killed upon illumination. DTPA-IRDye700DX-7D12 homed to A431 xenografts in vivo, and this could be visualized with both SPECT and fluorescence imaging. In conclusion, the dichlorotetrazine platform offers a feasible method for site-specific dual-labeling of VHH 7D12, retaining binding affinity and therapeutic efficacy. The flexibility of the described approach makes it easy to vary the nature of the probes for other combinations of diagnostic and therapeutic compounds.

Keywords: variable domain of heavy chain only antibodies (VHH); site-specific conjugation; duallabeling; nuclear imaging; photodynamic therapy 


\section{Introduction}

The variable domains of heavy chain only antibodies (VHHs or nanobodies ${ }^{\circledR}$ ) were discovered in the early 1990s. They are an interesting class of molecules for tumor imaging and therapy, mainly because of their small size ( $15 \mathrm{kDa}$ versus $150 \mathrm{kDa}$ for monoclonal antibodies) and fast clearance, leading to efficient tissue penetration [1] and good tumorto-background ratios at early time points post injection [2-10]. Furthermore, they are easily expressed recombinantly in bacterial or yeast systems, and very stable under harsh temperature or $\mathrm{pH}$ conditions.

To functionalize VHHs with diagnostics or therapeutic groups of interest, various conjugation methods have been employed. The most commonly used method is conjugation to naturally occurring lysine residues. Since often multiple lysines are present in VHHs, there is no control over the stoichiometry. Furthermore, if lysine residues are present in the antigen binding domain, conjugation can interfere with target binding. To this end, unpaired cysteines have been introduced at the C-terminus of the VHH, which can be site-specifically conjugated through maleimide chemistry [11]. Importantly, sitespecific labeling was shown to lead to preferable pharmacokinetics and tumor targeting potential [12].

A second site-specific conjugation method that is increasingly employed is the introduction of imaging probes or orthogonal clickable groups through sortase A-mediated transpeptidation of the LPETG amino acid sequence introduced in proteins [13-16]. The clickable groups enable further modification by cycloaddition reactions with the orthogonal click partner (e.g., another $\mathrm{VHH}$, a fluorophore or a therapeutic molecule).

Since the value of a theranostic approach, in which a targeting molecule can be used for both diagnosis and therapy, is increasingly appreciated, it would be advantageous to conjugate two functional groups to a VHH. Examples are a chelator for labeling with a radiometal and a fluorophore for either fluorescence guided surgery or targeted photodynamic therapy (tPDT). The radiometal can be used for nuclear imaging to localize and quantify target expression preoperatively, and for radioguidance to the tumor intraoperatively. Fluorescence imaging and tPDT can be used during surgery as well, to ensure complete resection and eradication of all tumor cells, respectively [17-20]. Besides application in the clinic, the presence of a radiometal is also advantageous for performing relatively easy and quantitative biodistribution studies of small compounds in vivo.

To achieve dual-labeling, maleimide chemistry and sortase A-mediated transpeptidation can be combined for introduction of two functional groups [21]. This procedure, however, is laborious and requires numerous incubation and purification steps, thereby also complicating clinical translation. Previously, our group has described dichlorotetrazine as a platform for site-specific dual-labeling of proteins [22,23]. We have shown that bimodal tetrazine-based probes, containing a chelator and a fluorophore, can readily be conjugated to a protein carrying a reactive alkene or alkyne group through the inverse electron demand Diels-Alder (iedDA) reaction. This method was illustrated by preparation of a bimodal antiHER2 monoclonal antibody for single photon emission computed tomography (SPECT) and fluorescence imaging [22].

In the current study, we performed the experiments with the extensively validated EGFR-targeting VHH 7D12 as a model. 7D12 has been investigated preclinically for cancer treatment as it sterically hinders natural ligand EGF from binding to EGFR [24], thereby inhibiting receptor activation and reducing cell proliferation $[25,26]$. Furthermore, 7D12 has been used for tumor imaging $[7,27,28]$ and tPDT [29-32]. Here, we employed the dichlorotetrazine platform for site-specific conjugation of the chelator diethylenetriaminepentaacetic acid (DTPA) and the photosensitizer IRDye700DX to 7D12 for application in a bimodal approach. We evaluated the function of the VHH for SPECT imaging and tPDT of EGFR-expressing tumors. 


\section{Results}

\subsection{Site-Specific Functionalization of Anti-EGFR VHH 7D12 with DTPA and IRDye700DX}

The bimodal probe DTPA-NH-Tz-S-IRDye700DX was synthesized in four steps (Figure S1). The detailed synthesis of the precursors as well as their analytical characterization are provided as supporting information (pages 6-11, Figures S2-S8). In short, $\mathrm{DTPA}(\mathrm{tBu})_{4}$ ester was condensed with ethylenediamine to obtain DTPA- $\mathrm{NH}_{2}$ after acidic deprotection (Figures S2 and S3). Then dichlorotetrazine was substituted with DTPA-NH $\mathrm{NH}_{2}$ at room temperature (Figures S4 and S5), and with Boc-mercaptoethylamine at $75{ }^{\circ} \mathrm{C}$ (Figures S6 and S7). Finally, IRDye700DX-NHS was coupled to the free amine group of the mercaptoethylamine at $25^{\circ} \mathrm{C}$ to obtain DTPA-NH-Tz-S-IRDye700DX with an overall yield of $18 \%$ (Figure S8).

The conjugate DTPA-IRDye700DX-7D12 was obtained in two steps (Figure 1). Detailed description and analysis is described in the supporting information (pages 12-16, Figures S9-S13). First, BCN-PEG 2 -maleimide (Figures S9 and S10) was site-specifically coupled to the unpaired cysteine residue of 7D12 (Figure S11). The conversion was complete with a protein recovery of $74 \%$ and a degree of labeling (DOL) of 1 . The subsequent click reaction between the bicyclonyne (BCN) and the tetrazine group of DTPA-NH-Tz-SIRDye700DX yielded the bimodal conjugate with a protein recovery yield of $43 \%$ and DOL of 0.56 (Figures S12 and S13).

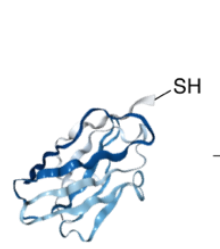

VHH 7D12

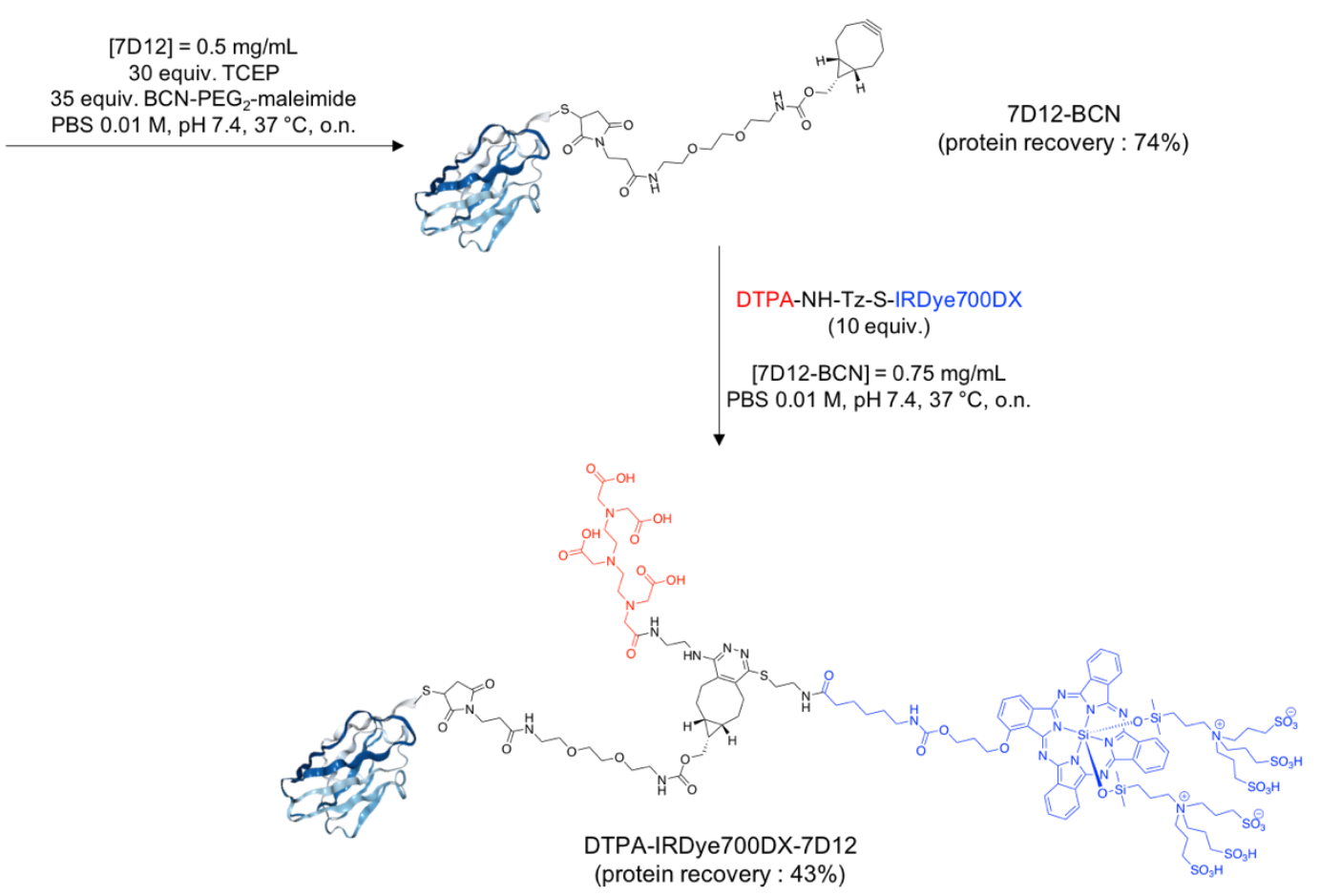

Figure 1. Synthesis of the bimodal conjugate DTPA-IRDye700DX-7D12.

Spectral properties of IRDye700DX were retained after conjugation to 7D12 (Figure 2 and Figures S14-S16), with excitation and emission maxima of $689 \mathrm{~nm}$ and $698 \mathrm{~nm}$, respectively. The fluorescence quantum yields of DTPA-IRDye700DX-7D12, DTPA-NHTz-S-IRDye700DX and IRDye700DX alone, were $0.12,0.21$ and 0.29 , respectively. DTPAIRDye700DX-7D12 produced singlet oxygen upon illumination with $690 \mathrm{~nm}$ light, albeit significantly lower when compared to non-conjugated IRDye700DX $(p<0.001$, Figure 2B). 
A

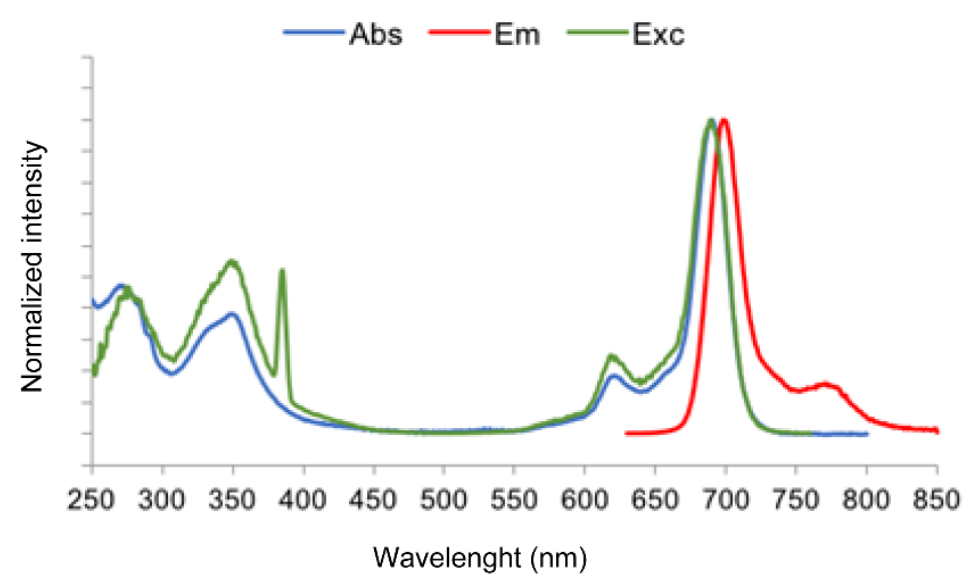

B

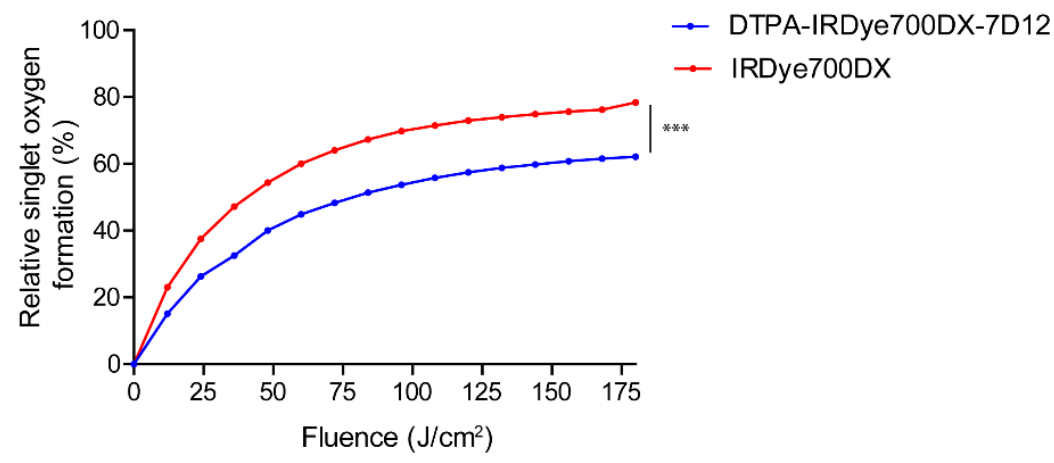

Figure 2. (A) Normalized photophysical spectra (absorbance, excitation and emission) of bimodal conjugate DTPA-IRDye700DX-7D12. (B) Formation of singlet oxygen upon illumination with $200 \mathrm{~mW} / \mathrm{cm}^{2} 690 \mathrm{~nm}$ light by IRDye700DX and conjugate DTPA-IRDye700DX-7D12. ${ }^{* * *} p<0.001$, as determined with two-way ANOVA for repeated measures with Bonferroni post-hoc test.

\section{2. [111 In]In-DTPA-IRDye700DX-7D12 Binds Specifically to EGFR-Expressing Cells}

For in vitro assays, DTPA-IRDye700DX-7D12 was labeled with $0.25 \mathrm{MBq} / \mu \mathrm{g}{ }^{111} \mathrm{In}$, yielding $>98 \%$ radiochemical purity. Labeling was stable in PBS and human serum in presence or absence of a molar excess of EDTA at $37^{\circ} \mathrm{C}$ for up to $24 \mathrm{~h}$ (Figure 3). Furthermore, LCMS performed after incubating the conjugate at radiolabeling-like conditions indicated stability of the product (supporting information, Figure S17).
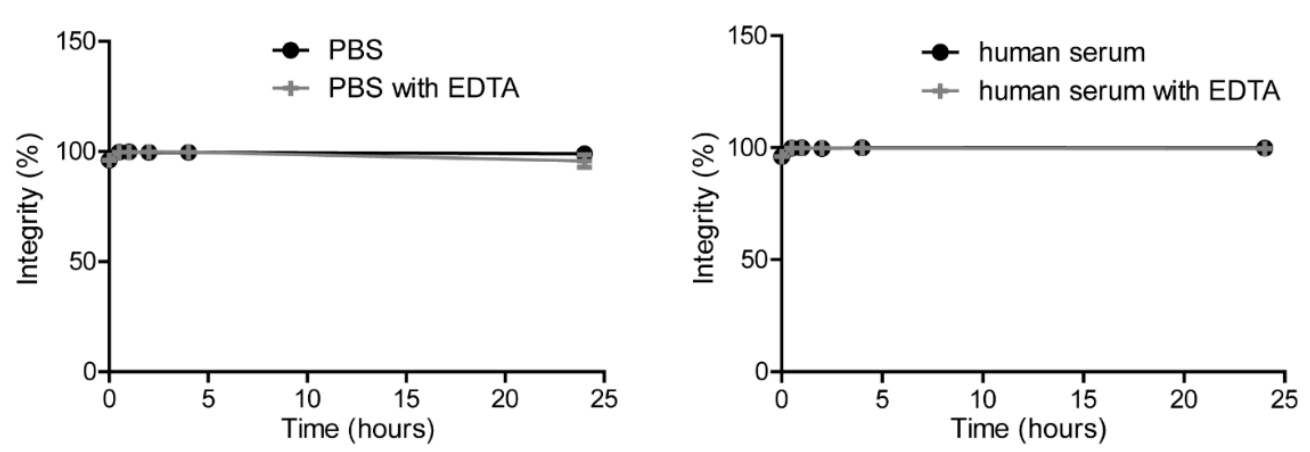

Figure 3. Stability of [ ${ }^{111} \mathrm{In}$ ]In-DTPA-IRDye700DX-7D12 in PBS (left graph) or human serum (right graph) in presence or absence of 1000-fold molar excess EDTA.

[111 In]In-DTPA-IRDye700DX-7D12 bound to A431 cells, with $11.20 \pm 0.33 \%$, $11.36 \pm 1.95 \%$ and $7.49 \pm 0.54 \%$ of added activity being membrane bound after 1,4 and 
$16 \mathrm{~h}$, respectively (Figure $4 \mathrm{~A}$ ). The tracer was efficiently internalized, with $7.85 \pm 0.81 \%$, $14.68 \pm 0.88 \%$ and $16.14 \pm 1.09 \%$ of added activity being intracellular after 1,4 and $16 \mathrm{~h}$, respectively. The minimal binding and internalization in presence of an excess of unlabeled 7D12 illustrated EGFR-specificity. Half maximal inhibitory concentrations $\left(\mathrm{IC}_{50}\right)$ of native 7D12 and DTPA-IRDye700DX-7D12 were $22.76 \mathrm{nM}$ and $18.11 \mathrm{nM}$, respectively (Figure 4B).

A

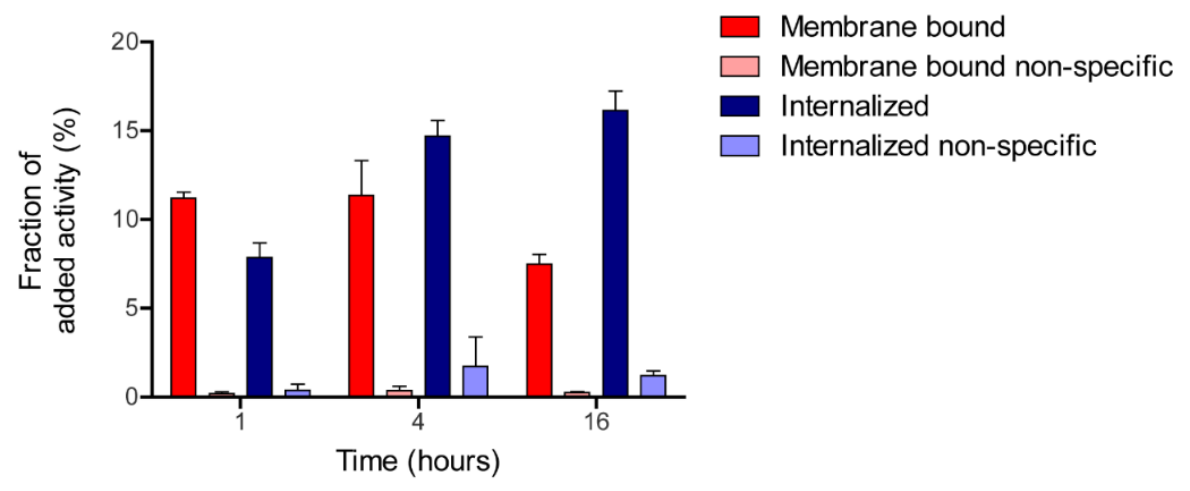

B

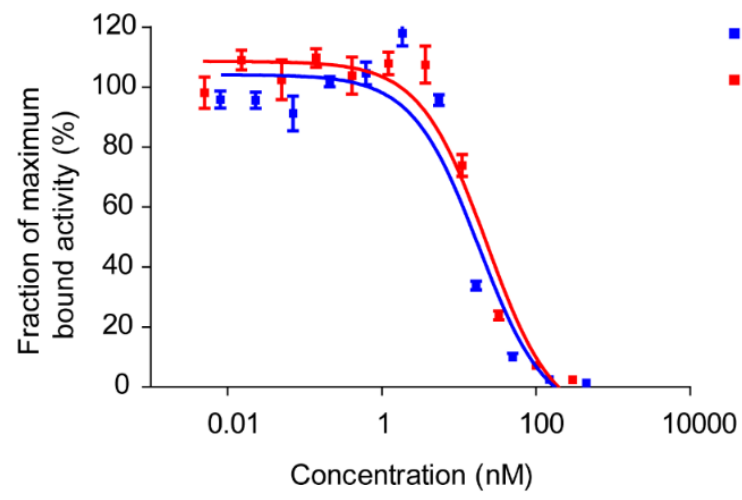

- DTPA-IRDye700DX-7D12

- 7D12

Figure 4. (A) Bound and internalized fractions of [ $\left.{ }^{111} \mathrm{In}\right]$ In-DTPA-IRDye700DX-7D12 after 1, 4 and $16 \mathrm{~h}$ of incubation at $37^{\circ} \mathrm{C}$, in absence or presence of an excess of unlabeled native 7D12. (B) Competition of cell associated [ ${ }^{111}$ In]In-DTPAIRDye700DX-7D12 by increasing concentrations of native 7D12 or unlabeled DTPA-IRDye700DX-7D12.

\subsection{DTPA-IRDye700DX-7D12 Induces Cell Death upon Illumination}

After incubation with DTPA-IRDye700DX-7D12, A431 cells were effectively killed upon illumination with $690 \mathrm{~nm}$ light. The effect was dependent on protein dose and total light dose in $\mathrm{J} / \mathrm{cm}^{2}$, whereas no clear correlation for light dose rate and efficacy was found (Figure 5A). To investigate the contribution of membrane bound and internalized fractions of the conjugate to cytotoxicity, cells that contain both fractions, and cells that only contain the internalized fraction were illuminated (Figure 5B). Cell viability was dose-dependently decreased by the intracellular fraction, and this effect was significantly larger when adding the membrane bound fraction $(p<0.001$ for $1.66,5$ and $15 \mathrm{~nm}$ when comparing intracellular and membrane bound with intracellular only), indicating that both fractions contribute to cytotoxicity. Singlet oxygen scavenger $N$-acetylcysteine (NAC) significantly reduced efficacy of the treatment after incubation with up to $1.66 \mathrm{nM}$ of the conjugate $(p<0.001)$ (Figure 5B). Only scavenging of extracellular singlet oxygen contributed to this effect, as no change in cytotoxicity was observed when using cells containing only the internalized fraction of the conjugate (Figure 5B). Finally, cells were incubated with either [ $\left.{ }^{111} \mathrm{In}\right] \mathrm{In}$ DTPA-IRDye700DX-7D12 or unlabeled DTPA-IRDye700DX-7D12. Both constructs induced cell death with equal efficiency upon illumination. For both constructs cytotoxic effect was absent without illumination (Figure 5C). 
A
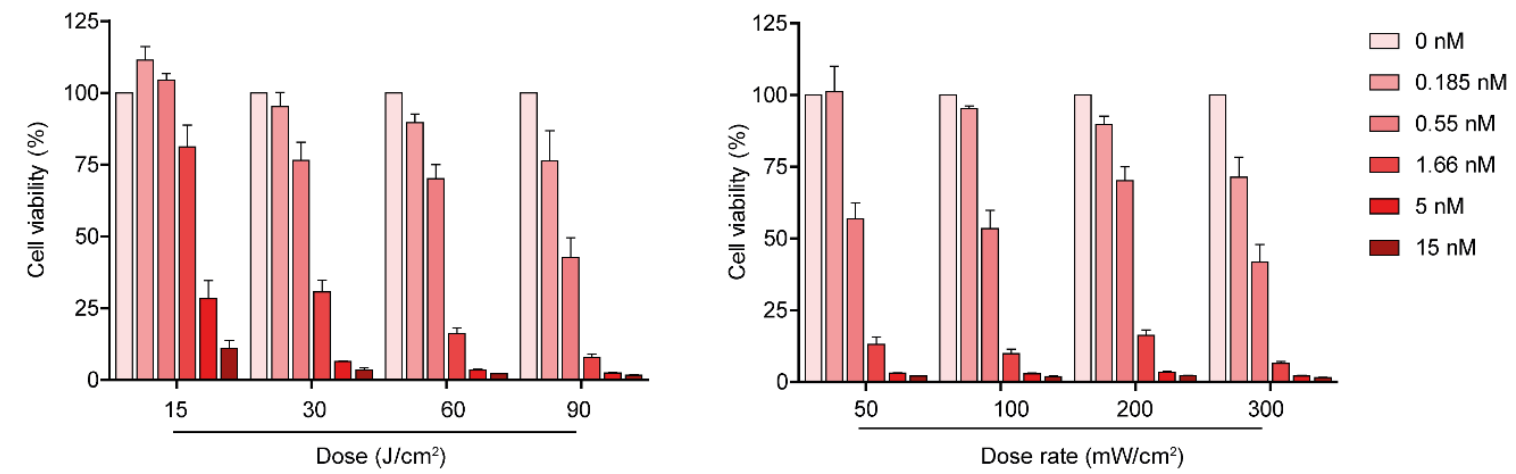

B

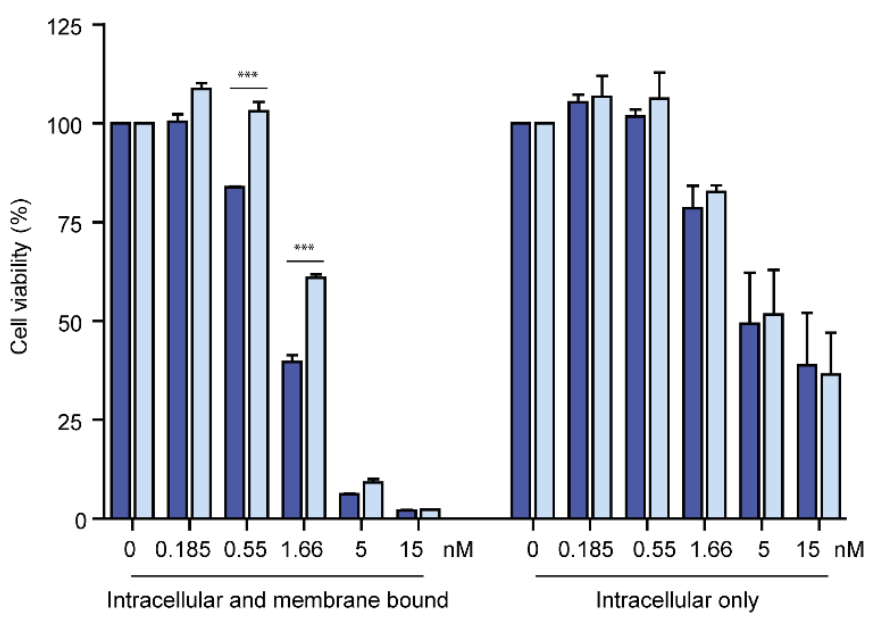

C

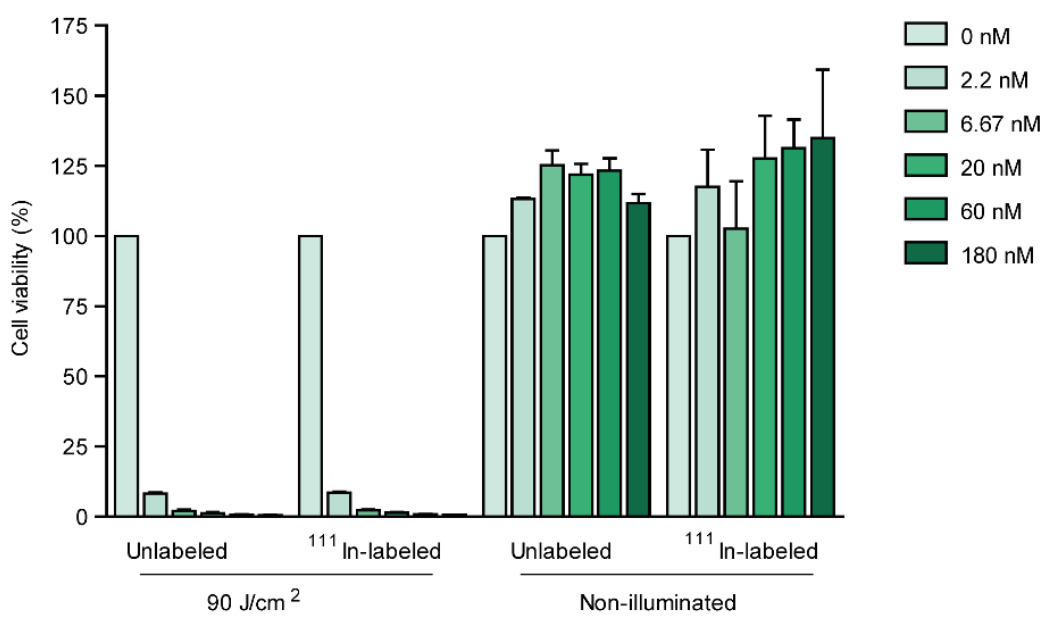

Figure 5. (A) DTPA-IRDye700DX-7D12 induces cell death of A431 cells upon illumination with varying light doses at a fixed light dose rate of $200 \mathrm{~mW} / \mathrm{cm}^{2}$ (left) and varying light dose rates (right) at a fixed dose of $60 \mathrm{~J} / \mathrm{cm}^{2}$ of $690 \mathrm{~nm}$ light. (B) Both internalized as well as membrane bound fractions of the conjugate contribute to light induced toxicity upon illumination with $60 \mathrm{~J} / \mathrm{cm}^{2} 690 \mathrm{~nm}$ light at $200 \mathrm{~mW} / \mathrm{cm}^{2}$. Incubation with singlet oxygen scavenger NAC partly inhibits the cytotoxic effect in cells containing both fractions, but not in cells containing only the intracellular fraction. (C) Both [111 In]In-DTPA-IRDye700DX-7D12 and unlabeled DTPA-IRDye700DX-7D12 induce toxicity with equal efficiency upon illumination with $90 \mathrm{~J} / \mathrm{cm}^{2} 690$ light at $200 \mathrm{~mW} / \mathrm{cm}^{2}$, without illumination no toxicity is observed. Significance is determined with two-way ANOVA with post-hoc Bonferroni ${ }^{* * *}=p<0.001$. 


\section{4. [ ${ }^{111}$ In]In-DTPA-IRDye700DX-7D12 Homes to EGFR-Expressing Tumors and Can Be Visualized with Imaging}

A protein dose escalation was performed in mice carrying subcutaneous A431 xenografts. Injection of 1, 5, 25 or $50 \mu \mathrm{g}$ [111 In]In-DTPA-IRDye700DX-7D12 (1 MBq) resulted in comparable relative tumor uptake of $4.76 \pm 0.3,4.5 \pm 1.16,5.16 \pm 0.48$ and $4.54 \pm 0.64 \% \mathrm{IA} / \mathrm{g}$, respectively (Figure 6A). Uptake was partly EGFR specific, as demonstrated by significantly lower tumor uptake upon co-injection of unlabeled cetuximab $(4.76 \pm 0.3 \% \mathrm{IA} / \mathrm{g}$ versus $2.94 \pm 0.79 \% \mathrm{IA} / \mathrm{g}, p=0.0201)$. Furthermore, high uptake in the kidneys, and uptake in the liver and spleen was observed for all concentrations, which could not be blocked by unlabeled cetuximab. The injected protein dose of $50 \mu \mathrm{g}$ led to the highest absolute tumor uptake $(2.27 \pm 0.31 \mu \mathrm{g} / \mathrm{g})$ (Figure 6B). Micro-SPECT (Figure 6C) and near infrared fluorescence imaging (Figure 6D) w ere performed, and the tracer could clearly be visualized with both modalities.

A

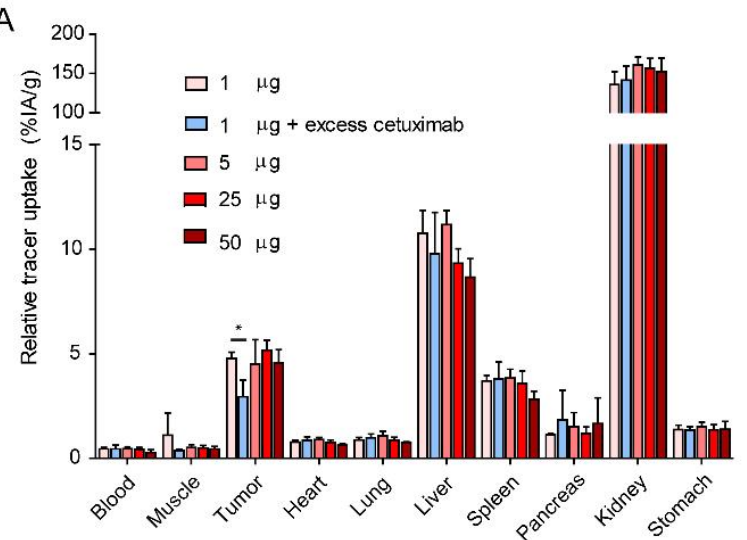

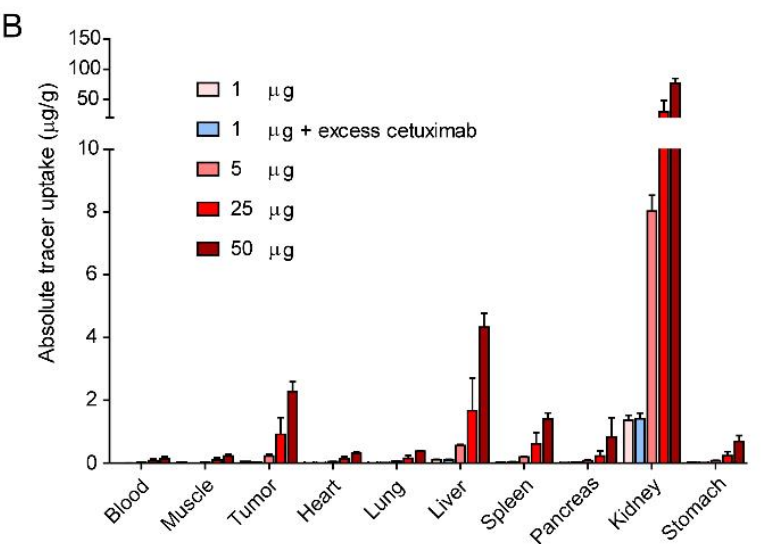

C

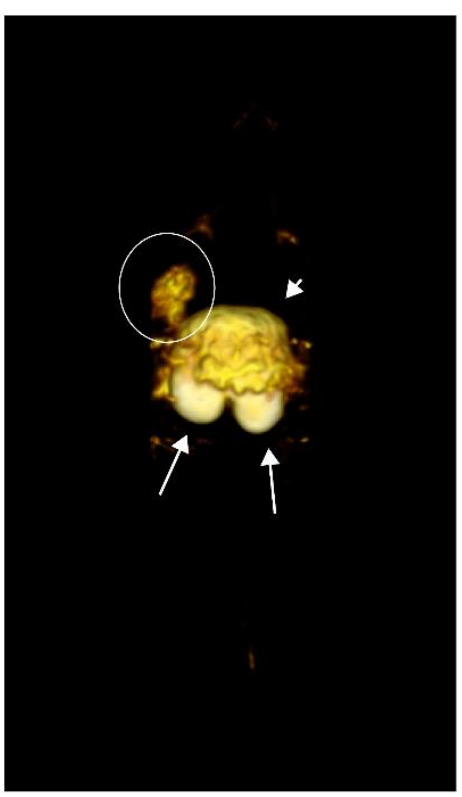

D

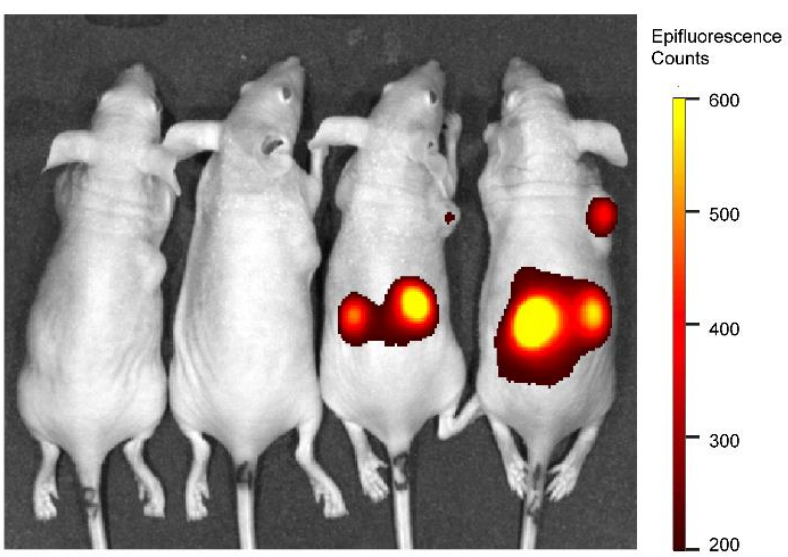

Figure 6. Ex vivo biodistribution of various protein doses of [ $\left.{ }^{111} \mathrm{In}\right] \mathrm{In}-\mathrm{DTPA}-\mathrm{IRDye700DX}-7 \mathrm{D} 12$ ( $\mathrm{n}=3$ per group) showing (A) relative tracer uptake and (B) absolute tracer uptake in EGFR-expressing tumors and other tissues. Statistical significance is determined with an unpaired T-test, ${ }^{*}=p<0.05$. (C) $\mu$ SPECT of a mouse $19 \mathrm{~h}$ after injection of $3 \mu \mathrm{g} 10 \mathrm{MBq}\left[{ }^{111} \mathrm{In}\right.$ ]InDTPA-IRDye700DX-7D12. Note the high uptake in kidneys (arrows), liver (arrowhead) and tumor (circle). (D) Near infrared fluorescence image of mice $16 \mathrm{~h}$ after injection of 1, 5, 25 or $50 \mu \mathrm{g} 1 \mathrm{MBq}$ [111 In]In-DTPA-IRDye700DX-7D12. At higher protein concentrations, uptake in kidneys and tumor is visualized. 


\section{Discussion}

It is well established that protein labeling can significantly alter the targeting properties and pharmacokinetics of proteins, especially in case of small proteins such as VHHs [12]. Here, we have demonstrated that the dichlorotetrazine platform can be used to introduce two modalities, a chelator and the fluorophore IRDye700DX, at a single site of a VHH.

The cysteine residue introduced at the C-terminus of anti-EGFR VHH 7D12 was equipped with $\mathrm{BCN}-\mathrm{PEG}_{2}$-maleimide to ensure selective labeling with the bimodal tetrazine probe. In future experiments, substitution of the $\mathrm{BCN}$ with the more reactive group transcyclooctene (TCO) could increase labeling efficiency [33]. Though IRDye700DX is a photostable phthalocyanine with favorable spectral properties and excellent water solubility [34], it is also a fragile and expensive molecule, and therefore we have enabled addition of IRDye700DX during the last stage of synthesis. The spectral properties of IRDye700DX were preserved after conjugation to 7D12, and conjugation did not affect $7 \mathrm{D} 12$ binding affinity as illustrated by similar $\mathrm{IC}_{50}$ values. The production of singlet oxygen upon illumination decreased upon conjugation but remained adequate for application in PDT.

Other efforts in site-specific dual-labeling entail sortase A-mediated labeling combined with maleimide [21] or $\pi$-clamp conjugation [35], however these procedures include multiple conjugation and purification steps, and in each step material is lost. Furthermore, our current approach ensures a 1:1 ratio between the radiolabel and the PDT dye conjugated to the protein, which guarantees a match between the SPECT signal and the area treated by PDT.

The scope of this study was to develop and implement a technique for site-specific dual-labeling of small proteins such as VHHs. For actual application of bimodal VHHs in a theranostic approach as described here, there are various factors to take into account. First, the rapid renal clearance of VHHs ensures since high tumor-to-background ratios at early time points post injection, but can also lead to low absolute tumor uptake, which negatively affects therapeutic efficacy. Alterations to elongate blood half-life [36], such as conjugation to polyethylene glycol (PEG) or albumin binding domains, are interesting in this respect. Furthermore, injection of high protein doses to achieve high absolute tumor uptake is convenient for therapeutic approaches, however it can induce receptor saturation and thereby decrease signal obtained in nuclear imaging. Finally, an optimal compromise between various factors such as protein dose, size, circulation time and the resulting absolute tumor uptake has to be found.

Ultimately, the bimodal $\mathrm{VHH}$ as described here can be applied in image guided therapy, by guiding the surgeon to a tumor lesion by radioactive signal, and by using photosensitizer's fluorescence and therapeutic effects for ablation of tumor cells. This therapy could be applied in oncologic surgical interventions in EGFR-expressing tumors, such as head-and-neck cancer, bladder cancer, lung cancer and brain tumors. Conjugates of EGFR-targeting monoclonal antibodies with IRDye700DX are currently being evaluated in a clinical setting for treatment of head-and-neck squamous cell carcinoma [37-39]. Due to their small size, VHHs have the advantage of more homogenous tissue penetration, leading to more efficient tumor targeting, also when applied in PDT [1,29]. Furthermore, binding to only a small epitope of EGFR, which completely overlaps with the EGF binding site, and the directly induced cytotoxic effect could prevent resistance through mutations of the EGFR ectodomain, which are frequently induced by therapeutic antibodies [40]. Though PDT has been shown to help overcoming drug resistance by for example stimulation of anti-tumor immunity and enhancement of drug delivery, intrinsic and acquired resistance mechanisms to PDT have been described as well [41]. These photobiological aspects of EGFR-directed PDT warrant more thorough investigation. 


\section{Materials and Methods}

\subsection{Production and Characterization of the Anti-EGFR VHH 7D12}

Anti-EGFR VHH 7D12 with a C-terminal CLPETG tag for maleimide and sortase A conjugations, a hexa-histidine for purification and a VSV tag for antibody-based detection was expressed and purified as described previously [30,42]. In short, ER2566 bacteria (stock was kindly provided by dr. W.P.J. Leenders) were grown in 2xTY medium, and VHH expression was induced with $1 \mathrm{mM}$ IPTG for $4 \mathrm{~h}$ at $30^{\circ} \mathrm{C}$. Subsequently the periplasmic fraction was collected, and VHHs were purified using Ni-NTA sepharose (IBA, Göttingen, Germany). Purity and size were characterized with sodium dodecyl sulfate polyacrylamide gel electrophoresis (SDS-PAGE) under reducing conditions and a coomassie brilliant blue staining. The concentration of the 7D12 in $\mathrm{g} / \mathrm{L}$ was calculated by UV spectrophotometry by using the extinction coefficient of 7D12 at $280 \mathrm{~nm}\left(35535 \mathrm{~L} \cdot \mathrm{mol}^{-1} \cdot \mathrm{cm}^{-1}\right)$.

\subsection{Synthesis of the Bimodal Probe}

The synthesis of the bimodal probe DTPA-NH-Tz-S-IRDye700DX was carried out using the methods described previously [22]. The detailed synthesis of the precursors as well as their analytical characterization are provided as supporting information (pages 6-11).

\subsection{Synthesis of $7 D 12-B C N$}

A detailed description of the synthesis of 7D12-BCN as well as the analytical characterization of the compound is provided in the supporting information (pages 12-14). To a $7.24 \mathrm{~g} / \mathrm{L}$ solution of VHH 7D12 in PBS (2 mg, $110 \mathrm{nmol})$ a $20 \mathrm{mM}$ solution of tris(2carboxyethyl)phosphine (TCEP) in PBS (637 $\mu \mathrm{g}, 2.24 \mu \mathrm{mol}, 20$ equiv.) and a $20 \mathrm{mM}$ solution of BCN-PEG ${ }_{2}$-maleimide in DMSO (1.06 mg, $2.24 \mu \mathrm{mol}, 20$ equiv.) were added. The solution was stirred at $37^{\circ} \mathrm{C}$ in a thermomixer $(900 \mathrm{rpm}$ ) for $7 \mathrm{~h}$. An additional amount of TCEP (318.5 $\mu \mathrm{g}, 1.12 \mu \mathrm{mol}, 10$ equiv.) and BCN-PEG 2 -maleimide in DMSO (795 $\mu \mathrm{g}$, $1.68 \mu \mathrm{mol}, 15$ equiv.) were added and the solution was stirred $\left(900 \mathrm{rpm}, 37^{\circ} \mathrm{C}\right)$ overnight. Excess of TCEP and BCN was removed by ultrafiltration on an Ultra Ultracel $3 \mathrm{kDa}(\mathrm{Am}-$ icon, Merck Millipore, Burlington, MA, USA). This ultrafiltration step also allowed the product to be concentrated and the DMSO to be removed. The VHH 7D12-BCN was obtained as a $3.69 \mathrm{~g} / \mathrm{L}$ solution in PBS $(1.48 \mathrm{mg}$, protein recovery $=74 \%)$. The degree of labeling was determined to be 1 by MALDI-TOF and HPLC-MS analyses.

\subsection{Site-Specific Labeling of 7D12-BCN with DTPA and IRDye700DX}

To a $3.69 \mathrm{~g} / \mathrm{L}$ solution of VHH 7D12-BCN in PBS (922 $\mu \mathrm{g}, 50.4 \mathrm{nmol}), 75.2 \mu \mathrm{L}$ of a $6.7 \mathrm{mM}$ stock solution of DTPA-NH-Tz-S-IRDye700DX in PBS (1.18 mg, $504 \mathrm{nmol}, 10$ equiv.) and $905 \mu \mathrm{L}$ of PBS were added. The solution was stirred in a thermomixer $\left(900 \mathrm{rpm}, 37^{\circ} \mathrm{C}\right)$ overnight. The product was purified by FPLC (Äkta Pure $25 \mathrm{M}$ chromatography system, GE Healthcare Life Sciences, Chicago, IL, USA) on a Superdex 75 10/300 GL column (cross-linked agarose and dextran, $13 \mu \mathrm{m}, 10 \times 300-10 \mathrm{~mm}, 24 \mathrm{~mL}$ ), at $0.8 \mathrm{~mL} / \mathrm{min}$, with phosphate buffer $(20 \mathrm{mM}, \mathrm{pH} 7.3)$ with $\mathrm{NaN}_{3}(0.05 \%)$ as eluent (Figure S12). The bimodal conjugate DTPA-IRDye700DX-7D12 was obtained as a $1.27 \mathrm{~g} / \mathrm{L}$ solution (444 $\mu \mathrm{g}$, protein recovery $=43 \%$ ). The degree of labeling was determined to be 0.56 (UV-visible spectroscopy). A correction factor (0.1) was introduced to account for the contribution of the phthalocyanine absorbance at $280 \mathrm{~nm}$. The molar concentration of the fluorophore was calculated by UV spectrophotometry by using the extinction coefficient of IRDye700DX at $689 \mathrm{~nm}$ in PBS $\left(165000 \mathrm{~L} \cdot \mathrm{mol}^{-1} \cdot \mathrm{cm}^{-1}\right)$. The analytical characterization of the compound is provided in the supporting information (Figure S13).

\subsection{Characterization of the Conjugate}

Spectral characterization of the compounds is provided in the supporting information (Figures S14-S16).

UV-visible spectra were recorded on a Cary 60 scan (double beam) spectrophotometer (Varian, Palo Alto, CA, USA) by using a rectangular quartz cell (100-QS, $45 \times 12.5 \times 12.5 \mathrm{~mm}$, 
pathlength: $10 \mathrm{~mm}$, chamber volume: $3.5 \mathrm{~mL}$, Hellma-France, Paris, France), at $25^{\circ} \mathrm{C}$ (using a temperature control system combined with water circulation). Fluorescence spectroscopic studies were performed with a Fluorolog spectrofluorometer (HORIBA Jobin Yvon, Palaiseau, France, software FluorEssence) at $25^{\circ} \mathrm{C}$, with a standard fluorometer cell (LB Q, light path: $10 \mathrm{~mm}$, width: $10 \mathrm{~mm}$, chamber volume: $50 \mu \mathrm{L}$, Labbox, Barcelona, Spain).

UV-Visible absorbance and fluorescence spectra of the IRDye700DX dye and related conjugates were recorded in the range $250-800 \mathrm{~nm}$ in PBS (pH 7.4, $0.01 \mathrm{M}$ ) with concentrations in the micromolar range. Emission spectra were recorded in the range 630-850 nm after excitation at $620 \mathrm{~nm}$ (shutter: Auto Open, Ex. Slit $=5 \mathrm{~nm}$ and Em. slit $=5 \mathrm{~nm}$ ). Excitation spectra were recorded in the range $250-760 \mathrm{~nm}$ with emission measurement at $770 \mathrm{~nm}$ (shutter: Auto Open, Ex. slit $=5 \mathrm{~nm}$ and Em. slit $=5 \mathrm{~nm}$ ). Fluorescence quantum yields were measured at $25^{\circ} \mathrm{C}$ by a relative method using a suitable standard (AzaBODIPY JPL04, $\Phi=0.36$, dilution by a factor of 3 between absorption and fluorescence measurements). The following equation was used:

$\Phi F_{X}=\left(A_{S} / A_{X}\right)\left(F_{X} / F_{S}\right)\left(n_{X} / n_{S}\right)^{2} \Phi F_{S}$ where $A$ is the absorbance (in the range of $0.01-$ 0.1 A.U.), where $\mathrm{F}$ is the area under the emission curve, $\mathrm{n}$ is the refractive index of the solvents (at $25^{\circ} \mathrm{C}$ ) used in measurements, and the subscripts $\mathrm{s}$ and $\mathrm{x}$ represent standard and unknown, respectively.

\subsection{Radiolabeling of DTPA-IRDye700DX-7D12 and Quality Control}

DTPA-IRDye700DX-7D12 was incubated with $\left[{ }^{111} \mathrm{In} \mathrm{InCl}_{3}\right.$ (Curium, Petten, The Netherlands) and twice the volume of 0.5 M 2-(N-morpholino)ethanesulfonic (MES) buffer, pH 5.5 for $30 \mathrm{~min}$ at room temperature. Labeling efficiency and radiochemical purity were determined by instant thin-layer chromatography (iTLC) on a silica gel chromatography strip (Biodex, Shirley, NY, USA), using $0.1 \mathrm{M}$ citrate buffer $\mathrm{pH} 6.0$ as the mobile phase. For stability and in vitro studies, labeling was performed at $0.25 \mathrm{MBq} / \mu \mathrm{g}$. Stability of labeling up to $24 \mathrm{~h}$ was determined by iTLC after incubating $180 \mathrm{nM}$ of the labeled construct in either human serum or PBS with or without a thousand-fold molar excess of ethylenediaminetetraacetic acid (EDTA). Furthermore, stability of the construct in labeling conditions was determined by HPLC-MS analyses after 0,2 and $4 \mathrm{~h}$ (supporting information, Figure S17). For in vivo studies, labeling was performed at $3 \mathrm{MBq} / \mu \mathrm{g}$ and the labeled product was purified on a PD-10 column (GE, Woerden, The Netherlands), that was eluted with PBS 0.5\% BSA.

\subsection{Singlet Oxygen Production by DTPA-IRDye700DX-7D12 upon Illumination}

DTPA-IRDye700DX-7D12 (250 nM) was incubated with p-nitrosodimethylaniline (RNO; $50 \mu \mathrm{M})$ and imidazole $(400 \mu \mathrm{M})$ as an acceptor of ${ }^{1} \mathrm{O}_{2}$ in phosphate buffered saline pH 7.4 in clear flat-bottom 96-wells plates (Corning Costar, Corning, NY, USA), and illuminated with $690 \mathrm{~nm}$ light at $200 \mathrm{~mW} / \mathrm{cm}^{2}$. Absorbance at $440 \mathrm{~nm}$ was measured every minute with the Tecan Infinite ${ }^{\circledR} 200$ Pro (Tecan, Männedorf, Switzerland), to determine ${ }^{1} \mathrm{O}_{2}$ induced bleaching of RNO.

\subsection{Cell Culture}

The human epidermoid carcinoma cell line A431, carrying an amplification of the EGFR gene, [43] was cultured in RPMI-1640 (GIBCO, Thermo-Fisher Scientific, Waltham, MA, USA), supplemented with $2 \mathrm{mmol} / \mathrm{L}$ L-glutamine (GIBCO, Thermo-Fisher Scientific) and 10\% FCS (Sigma-Aldrich, St. Louis, MO, USA). During all in vitro assays, cells were incubated at $37^{\circ} \mathrm{C}$, in a humidified atmosphere with $5 \% \mathrm{CO}_{2}$, unless stated otherwise.

\subsection{In Vitro Binding and Internalization of DTPA-IRDye700DX-7D12}

A431 cells were plated at 60,000 cells / well in 6-wells plates and grown to $80 \%$ confluency in 3 days. Cells were incubated with $1600 \mathrm{~Bq}\left[{ }^{111}\right.$ In]In-DTPA-IRDye700DX-7D12 in RPMI with $0.5 \%$ BSA (RPMI-BSA) for 1,4 and $16 \mathrm{~h}$. EGFR specificity of binding was assessed by co-incubation with $15 \mu \mathrm{g}$ unlabeled 7D12 per well. After incubation, cells were 
washed twice with PBS, and the receptor-bound [111 In]In-DTPA-IRDye700DX-7D12 was retrieved by incubation with ice-cold $0.1 \mathrm{M}$ acetic acid, $154 \mathrm{M} \mathrm{NaCl}, \mathrm{pH} 2.6$ for $10 \mathrm{~min}$ on ice. After washing twice with PBS, cells containing the internalized $\left.{ }^{111} \mathrm{In}\right] \mathrm{In}$-DTPAIRDye700DX-7D12 were collected with $1 \mathrm{~mL} 0.1 \mathrm{M} \mathrm{NaOH}$. Activity in both fractions was counted in a $\gamma$-counter (2480 Wizard 3", LKB/Wallace, Perkin-Elmer, Boston, MA, USA). Specific binding and internalization were calculated by subtracting the non-specific signal from the total signal.

\subsection{0. $I C_{50}$ Assay}

A431 cells were plated at 60,000 cells/well in 6-wells plates, and grown to $80 \%$ confluency in 3 days. Cells were incubated with increasing concentrations of either unlabeled DTPA-IRDye700DX-7D12 or native 7D12 (0.005 to $450 \mathrm{nM})$ in RPMI-BSA, in presence of $1600 \mathrm{~Bq}$ of [ $\left.{ }^{111} \mathrm{In}\right] \mathrm{In}-\mathrm{DTPA}-I R D y e 700 \mathrm{DX}-7 \mathrm{D} 12 \mathrm{for} 4 \mathrm{~h}$ on ice. Subsequently, cells were washed twice with PBS, and collected with $1 \mathrm{~mL} 0.1 \mathrm{M} \mathrm{NaOH}$. Activity in all fractions was counted in a $\gamma$-counter (2480 Wizard 3", LKB/Wallace, Perkin-Elmer). The $\mathrm{IC}_{50}$ values (the concentrations of DTPA-IRDye700DX-7D12 or 7D12 needed to replace $50 \%$ of the bound

${ }^{111}$ In-labeled DTPA-IRDye700DX-7D12) were calculated in GraphPad Prism version 5.0 (GraphPad Software, San Diego, CA, USA).

\subsection{In Vitro Photodynamic Therapy_ ${ }^{111}$ In-Labeled Versus Unlabeled DTPA-IRDye700DX-7D12}

A431 cells were plated at 5000 cells per well in 96 wells plates and grown to 50\% confluency in 2 days. Then cells were incubated for $4 \mathrm{~h}$ with increasing concentrations of ${ }^{111}$ In-labeled or unlabeled DTPA-IRDye700DX-7D12 in RPMI-BSA. Upon washing twice with PBS, culture medium was added to the wells, and cells were illuminated with $90 \mathrm{~J} / \mathrm{cm}^{2}$ $690 \mathrm{~nm}$ light at a dose rate of $200 \mathrm{~mW} / \mathrm{cm}^{2}$ using a light emitting diode. Non-illuminated cells were taken as control to determine dark toxicity of the conjugates. The next day, cell viability was determined with the CellTiter-Glo ${ }^{\circledR}$ luminescence cell viability assay (Promega, Madison, WI, USA), according to manufacturer's protocol.

\subsection{In Vitro Photodynamic Therapy-The Effect of Acid Wash, Light Dose (Rate) and Singlet Oxygen Scavenging}

A431 cells were plated at 5000 cells per well in 96 wells plates, and grown to 50\% confluency in 2 days. Then cells were incubated for $3 \mathrm{~h}$ with increasing concentrations of unlabeled DTPA-IRDye700DX-7D12 in RPMI-BSA. Upon washing twice with PBS, part of the wells were incubated with ice-cold $0.1 \mathrm{M}$ acetic acid, $154 \mathrm{M} \mathrm{NaCl}, \mathrm{pH} 2.6$ for $10 \mathrm{~min}$ on ice to remove the membrane bound fraction of the conjugate. Upon washing twice with PBS, RPMI-BSA with or without $15 \mathrm{mM}$-acetyl cysteine (NAC) (Thermo-Fisher Scientific, Waltham, MA, USA) was added to the wells and incubated for $1 \mathrm{~h}$. Subsequently, cells were illuminated with various light doses $\left(30 \mathrm{~J} / \mathrm{cm}^{2}-90 \mathrm{~J} / \mathrm{cm}^{2}\right)$ at various light dose rates $\left(50 \mathrm{~mW} / \mathrm{cm}^{2}-200 \mathrm{~mW} / \mathrm{cm}^{2}\right)$ using a $690 \mathrm{~nm}$ light-emitting diode [44]. RPMI-BSA was replaced with culture medium. The next day, cell viability was determined with the CellTiter-Glo ${ }^{\circledR}$ luminescence cell viability assay (Promega, Madison, WI, USA), according to manufacturer's protocol.

\subsection{Ex Vivo Biodistribution and In Vivo SPECT and Fluorescence Imaging}

Animal studies were approved by the Central Authority for Scientific Procedures on Animals (RU-DEC-2015-0071) and carried out under supervision of the local Animal Welfare Body. Tumor targeting by DTPA-IRDye700DX-7D12 was determined in a biodistribution and imaging study in mice bearing A431 xenografts. Mice ( $\mathrm{n}=3$ per group) were injected subcutaneously on the right shoulder with $2.5 \times 10^{6}$ A431 cells in $200 \mu \mathrm{L}$ RPMI. After 9 days of tumor growth, when tumor size was $\sim 100-200 \mathrm{~mm}^{3}$, mice were injected intravenously with various protein doses of [111 In]In-DTPA-IRDye700DX-7D12 (1 MBq in PBS $0.5 \% \mathrm{BSA})$. To determine the specificity of EGFR targeting, a separate group $(\mathrm{n}=3)$ was injected intravenously with a blocking dose of $1 \mathrm{mg}$ unlabeled cetuximab at 
$48 \mathrm{~h}$ prior to $1 \mu \mathrm{g}\left[{ }^{111} \mathrm{In}\right] \mathrm{In}-\mathrm{DTPA}-I R D y e 700 \mathrm{DX}-7 \mathrm{D} 12$ injection. Mice were euthanized by $\mathrm{CO}_{2}$ suffocation at $16 \mathrm{~h}$ after tracer injection, and near infrared fluorescence imaging of the mice was performed using the IVIS Lumina closed-cabinet fluorescence scanner (Caliper LifeSciences, Waltham, MA USA), excitation $640 \mathrm{~nm}$, autofluorescence correction excitation $535 \mathrm{~nm}$; both measured with the Cy5.5 filter). Tumors and other tissue samples (blood, muscle, liver, lung, kidney, spleen, pancreas and stomach) were harvested and weighed, and radioactivity in these samples was determined in a $\gamma$-counter (2480 Wizard 3", LKB/Wallace, Perkin-Elmer, Waltham, MA, USA). Radioactivity concentrations were calculated as percentage of the injected activity per gram of tissue $(\% \mathrm{IA} / \mathrm{g})$ and corrected for decay using injection standards. Additionally, one mouse was injected with $3 \mu \mathrm{g}$ DTPAIRDye700DX-7D12 labeled with $10 \mathrm{MBq}$ indium-111. $19 \mathrm{~h}$ post injection it was euthanized and imaged for $1 \mathrm{~h}$ using a U-SPECT/CT-II (MILabs, Utrecht, The Netherlands). The image was acquired using a $1 \mathrm{~mm}$ diameter pinhole ultra-high sensitivity mouse collimator. The SPECT scan was reconstructed using software from MILabs, using an $0.4 \mathrm{~mm}$ voxel size, one iteration and 16 subsets, and visualized in Inveon Research Workplace software (version 3.0; Siemens Preclinical Solutions, München, Germany).

\subsection{Statistics}

Graphpad Prism was used for statistical analyses. Statistical significance was determined with unpaired $t$-test or two-way ANOVA with post-hoc Bonferroni. ${ }^{*}=p<0.05$; ${ }^{* *}=p<0.01^{* * *}=p<0.001$.

\section{Conclusions}

In conclusion, we have applied an innovative method for site-specific dual-labeling of an unpaired cysteine in VHHs. This approach can easily be translated to other small proteins that are interesting for imaging and therapy such as DARPins and affibodies. Furthermore, as it is easy to vary the nature of the bimodal probe, it is a highly flexible system for introduction of a variety of therapeutic or diagnostic modalities, without affecting the target-binding domain of the proteins. Application of this conjugation method increases the feasibility of using bimodal small proteins in the field of tumor theranostics.

Supplementary Materials: The following are available online at https: / /www.mdpi.com/2072-669 4/13/3/428/s1, Figure S1: Synthesis of the bimodal probe DTPA-NH-Tz-S-IRDye700DX; Figure S2: RP-HPLC-MS analysis of DTPA-NH 2 . (Top) RP-HPLC chromatogram. (Bottom) ESI (+)-LRMS and UV-Vis absorbance spectrum; Figure S3: HRMS analysis of DTPA-NH $\mathrm{N}_{2}$; Figure S4: RP-HPLC-MS analysis of DTPA-NH-Tz-Cl (Top) RP-HPLC chromatogram. (Bottom) ESI (+)-LRMS and UV-Vis absorbance spectrum; Figure S5: HRMS analysis of DTPA-NH-Tz-Cl; Figure S6: RP-HPLC-MS analysis of DTPA-NH-Tz-NH2 . (Top) RP-HPLC chromatogram. (Bottom) ESI (+)-LRMS and UV-Vis absorbance spectrum; Figure S7: HRMS analysis of DTPA-NH-Tz-NH ${ }_{2}$; Figure S8: RP-HPLC-MS analysis of compound DTPA-NH-Tz-S-IRDye700DX (Top) RP-HPLC chromatogram. (Bottom) ESI (+)LRMS and UV-Vis absorbance spectrum; Figure S9: RP-HPLC-MS analysis of BCN-PEG ${ }_{2}$-maleimide. (Top) RP-HPLC chromatogram. (Bottom) ESI (+)-LRMS and UV-Vis absorbance spectrum; Figure S10: HRMS analysis of BCN-PEG 2 -maleimide; Figure S11: RP-HPLC-MS (Orbitrap) analysis of compound 7D12-BCN. A. (Top) RP-HPLC chromatograms (TIC and $280 \mathrm{~nm}$ ). (Bottom) Multicharged ESI-MS spectrum. B. Deconvoluted MS spectrum of native 7D12, reduced 7D12 and 7D12-BCN; Figure S12: FPLC purification chromatogram of the compound DTPA-IRDye700DX-7D12; Figure S13: RP-HPLCMS (Orbitrap) analysis of compound DTPA-IRDye700DX-7D12. A. (Top) RP-HPLC chromatograms (TIC, $280 \mathrm{~nm}$ and $650 \mathrm{~nm}$ ). (Bottom) Multicharged ESI-MS spectrum. B. Deconvoluted MS spectrum of reduced 7D12, 7D12-BCN and DTPA-IRDye700DX-7D12; Figure S14: Normalized photophysical spectra (absorbance, excitation and emission) of compound IRDye700DX. $\lambda_{\mathrm{Ex}, \max }=689 \mathrm{~nm}, \lambda_{\mathrm{Em}, \max }$ = $701 \mathrm{~nm}$; Figure S15: Normalized photophysical spectra (absorbance, excitation and emission) of bimodal probe DTPA-NH-Tz-S-IRDye700DX. $\lambda_{\mathrm{Ex}, \max }=689 \mathrm{~nm}, \lambda_{\mathrm{Em}, \max }=700 \mathrm{~nm}$; Figure S16: Normalized photophysical spectra (absorbance, excitation and emission) of bimodal conjugate DTPAIRDYe700DX-7D12. $\lambda_{E x, \max }=689 \mathrm{~nm}, \lambda_{\mathrm{Em}, \max }=698 \mathrm{~nm}$; Figure S17: RP-HPLC-MS chromatograms 
(TIC, $280 \mathrm{~nm}$ and $650 \mathrm{~nm}$ ) of compound DTPA-IRDye700DX-7D12 after $0 \mathrm{~min}, 2 \mathrm{~h}$ and $4 \mathrm{~h}$ of incubation in radiolabeling-like conditions.

Author Contributions: Conceptualization, S.A.M.v.L. and V.G.; methodology, S.A.M.v.L. and V.G.; formal analysis, E.R., E.C.C., C.C.; investigation, E.R., E.C.C., C.C., A.K.; writing-original draft preparation, S.A.M.v.L., E.R. and V.G.; writing-review and editing, E.C.C., C.C., A.K., M.G., M.R., F.D.; supervision, S.A.M.v.L., V.G. All authors have read and agreed to the published version of the manuscript.

Funding: This work received partial support by EFRO Proeftuin Nanomedicine, Operationeel programma Oost-Nederland (PROJ-00722), a Radboud Institute for Molecular Life Sciences (RIMLS) Junior Researcher grant, the French National Research Agency (ANR-17-CE18-0016-01), the CNRS, the Universite de Bourgogne, and by the European Union through the PO FEDER-FSE 2014/2020 Bourgogne program.

Institutional Review Board Statement: Animal studies were approved by the Central Authority for Scientific Procedures on Animals (RU-DEC-2015-0071) and carried out under supervision of the local Animal Welfare Body.

Informed Consent Statement: Not applicable.

Data Availability Statement: The data presented in this study are available on request from the corresponding author, as no public datasets for these preclinical data are generated.

Conflicts of Interest: The authors declare no conflict of interest.

\section{References}

1. Debie, P.; Lafont, C.; Defrise, M.; Hansen, I.; van Willigen, D.M.; van Leeuwen, F.W.B.; Gijsbers, R.; D’Huyvetter, M.; Devoogdt, N.; Lahoutte, T.; et al. Size and affinity kinetics of nanobodies influence targeting and penetration of solid tumours. J. Control. Release 2020, 317, 34-42. [CrossRef] [PubMed]

2. Xavier, C.; Vaneycken, I.; D’Huyvetter, M.; Heemskerk, J.; Keyaerts, M.; Vincke, C.; Devoogdt, N.; Muyldermans, S.; Lahoutte, T.; Caveliers, V. Synthesis, preclinical validation, dosimetry, and toxicity of 68Ga-NOTA-anti-HER2 Nanobodies for iPET imaging of HER2 receptor expression in cancer. J. Nucl. Med. 2013, 54, 776-784. [CrossRef] [PubMed]

3. Keyaerts, M.; Xavier, C.; Heemskerk, J.; Devoogdt, N.; Everaert, H.; Ackaert, C.; Vanhoeij, M.; Duhoux, F.P.; Gevaert, T.; Simon, P.; et al. Phase I Study of 68Ga-HER2-Nanobody for PET/CT Assessment of HER2 Expression in Breast Carcinoma. J. Nucl. Med. 2016, 57, 27-33. [CrossRef] [PubMed]

4. $\quad$ Broisat, A.; Hernot, S.; Toczek, J.; De Vos, J.; Riou, L.M.; Martin, S.; Ahmadi, M.; Thielens, N.; Wernery, U.; Caveliers, V.; et al. Nanobodies targeting mouse/human VCAM1 for the nuclear imaging of atherosclerotic lesions. Circ. Res. 2012, 110, 927-937. [CrossRef] [PubMed]

5. Blykers, A.; Schoonooghe, S.; Xavier, C.; D’Hoe, K.; Laoui, D.; D’Huyvetter, M.; Vaneycken, I.; Cleeren, F.; Bormans, G.; Heemskerk, J.; et al. PET Imaging of Macrophage Mannose Receptor-Expressing Macrophages in Tumor Stroma Using 18F-Radiolabeled Camelid Single-Domain Antibody Fragments. J. Nucl. Med. 2015, 56, 1265-1271. [CrossRef]

6. Vaneycken, I.; Devoogdt, N.; Van Gassen, N.; Vincke, C.; Xavier, C.; Wernery, U.; Muyldermans, S.; Lahoutte, T.; Caveliers, V. Preclinical screening of anti-HER2 nanobodies for molecular imaging of breast cancer. FASEB J. 2011, 25, 2433-2446. [CrossRef]

7. Oliveira, S.; van Dongen, G.A.; Stigter-van Walsum, M.; Roovers, R.C.; Stam, J.C.; Mali, W.; van Diest, P.J.; van Bergen en Henegouwen, P.M. Rapid visualization of human tumor xenografts through optical imaging with a near-infrared fluorescent anti-epidermal growth factor receptor nanobody. Mol. Imaging 2012, 11, 33-46. [CrossRef]

8. Kijanka, M.; Warnders, F.J.; El Khattabi, M.; Lub-de Hooge, M.; van Dam, G.M.; Ntziachristos, V.; de Vries, L.; Oliveira, S.; van Bergen En Henegouwen, P.M. Rapid optical imaging of human breast tumour xenografts using anti-HER2 VHHs site-directly conjugated to IRDye 800CW for image-guided surgery. Eur. J. Nucl. Med. Mol. Imaging 2013, 40, 1718-1729. [CrossRef]

9. Kijanka, M.M.; van Brussel, A.S.; van der Wall, E.; Mali, W.P.; van Diest, P.J.; van Bergen En Henegouwen, P.M.; Oliveira, S. Optical imaging of pre-invasive breast cancer with a combination of VHHs targeting CAIX and HER2 increases contrast and facilitates tumour characterization. EJNMMI Res. 2016, 6, 14. [CrossRef]

10. van Brussel, A.S.; Adams, A.; Oliveira, S.; Dorresteijn, B.; El Khattabi, M.; Vermeulen, J.F.; van der Wall, E.; Mali, W.P.; Derksen, P.W.; van Diest, P.J.; et al. Hypoxia-Targeting Fluorescent Nanobodies for Optical Molecular Imaging of Pre-Invasive Breast Cancer. Mol. Imaging Biol. 2016, 18, 535-544. [CrossRef]

11. Massa, S.; Xavier, C.; De Vos, J.; Caveliers, V.; Lahoutte, T.; Muyldermans, S.; Devoogdt, N. Site-specific labeling of cysteine-tagged camelid single-domain antibody-fragments for use in molecular imaging. Bioconj. Chem. 2014, 25, 979-988. [CrossRef] [PubMed]

12. Debie, P.; Van Quathem, J.; Hansen, I.; Bala, G.; Massa, S.; Devoogdt, N.; Xavier, C.; Hernot, S. Effect of Dye and Conjugation Chemistry on the Biodistribution Profile of Near-Infrared-Labeled Nanobodies as Tracers for Image-Guided Surgery. Mol. Pharm. 2017, 14, 1145-1153. [CrossRef] [PubMed] 
13. Witte, M.D.; Cragnolini, J.J.; Dougan, S.K.; Yoder, N.C.; Popp, M.W.; Ploegh, H.L. Preparation of unnatural N-to-N and C-to-C protein fusions. Proc. Natl. Acad. Sci. USA 2012, 109, 11993-11998. [CrossRef] [PubMed]

14. Alt, K.; Paterson, B.M.; Westein, E.; Rudd, S.E.; Poniger, S.S.; Jagdale, S.; Ardipradja, K.; Connell, T.U.; Krippner, G.Y.; Nair, A.K.; et al. A versatile approach for the site-specific modification of recombinant antibodies using a combination of enzyme-mediated Bioconj.ation and click chemistry. Angew Chem. Int. Ed. Engl. 2015, 54, 7515-7519. [CrossRef] [PubMed]

15. Witte, M.D.; Theile, C.S.; Wu, T.; Guimaraes, C.P.; Blom, A.E.; Ploegh, H.L. Production of unnaturally linked chimeric proteins using a combination of sortase-catalyzed transpeptidation and click chemistry. Nat. Protoc. 2013, 8, 1808-1819. [CrossRef] [PubMed]

16. Massa, S.; Vikani, N.; Betti, C.; Ballet, S.; Vanderhaegen, S.; Steyaert, J.; Descamps, B.; Vanhove, C.; Bunschoten, A.; van Leeuwen, F.W.; et al. Sortase A-mediated site-specific labeling of camelid single-domain antibody-fragments: A versatile strategy for multiple molecular imaging modalities. Contrast Media Mol. Imaging 2016, 11, 328-339. [CrossRef]

17. Hernandez Vargas, S.; Ghosh, S.C.; Azhdarinia, A. New Developments in Dual-Labeled Molecular Imaging Agents. J. Nucl. Med. 2019, 60, 459-465. [CrossRef]

18. Thorp-Greenwood, F.L.; Coogan, M.P. Multimodal radio-(PET/SPECT) and fluorescence imaging agents based on metalloradioisotopes: Current applications and prospects for development of new agents. Dalton Trans. 2011, 40, 6129-6143. [CrossRef]

19. Hekman, M.C.H.; Rijpkema, M.; Bos, D.L.; Oosterwijk, E.; Goldenberg, D.M.; Mulders, P.F.A.; Boerman, O.C. Detection of Micrometastases Using SPECT/Fluorescence Dual-Modality Imaging in a CEA-Expressing Tumor Model. J. Nucl. Med. 2017, 58, 706-710. [CrossRef]

20. Renard, E.; Dancer, P.A.; Portal, C.; Denat, F.; Prignon, A.; Goncalves, V. Design of Bimodal Ligands of Neurotensin Receptor 1 for Positron Emission Tomography Imaging and Fluorescence-Guided Surgery of Pancreatic Cancer. J. Med. Chem. 2020, 63, 2426-2433. [CrossRef]

21. van Lith, S.A.; van Duijnhoven, S.M.; Navis, A.C.; Leenders, W.P.; Dolk, E.; Wennink, J.W.; van Nostrum, C.F.; van Hest, J.C. Legomedicine-A Versatile Chemo-Enzymatic Approach for the Preparation of Targeted Dual-Labeled Llama AntibodyNanoparticle Conjugates. Bioconj. Chem. 2017, 28, 539-548. [CrossRef] [PubMed]

22. Canovas, C.; Moreau, M.; Vrigneaud, J.M.; Bellaye, P.S.; Collin, B.; Denat, F.; Goncalves, V. Modular Assembly of Multimodal Imaging Agents through an Inverse Electron Demand Diels-Alder Reaction. Bioconj. Chem. 2019, 30, 888-897. [CrossRef] [PubMed]

23. Canovas, C.; Moreau, M.; Bernhard, C.; Oudot, A.; Guillemin, M.; Denat, F.; Goncalves, V. Site-Specific Dual Labeling of Proteins on Cysteine Residues with Chlorotetrazines. Angew Chem. Int. Ed. Engl. 2018, 57, 10646-10650. [CrossRef] [PubMed]

24. Schmitz, K.R.; Bagchi, A.; Roovers, R.C.; van Bergen en Henegouwen, P.M.; Ferguson, K.M. Structural evaluation of EGFR inhibition mechanisms for nanobodies/VHH domains. Structure 2013, 21, 1214-1224. [CrossRef] [PubMed]

25. Roovers, R.C.; Laeremans, T.; Huang, L.; De Taeye, S.; Verkleij, A.J.; Revets, H.; de Haard, H.J.; van Bergen en Henegouwen, P.M. Efficient inhibition of EGFR signaling and of tumour growth by antagonistic anti-EFGR Nanobodies. Cancer Immunol. Immunother. 2007, 56, 303-317. [CrossRef]

26. Roovers, R.C.; Vosjan, M.J.; Laeremans, T.; el Khoulati, R.; de Bruin, R.C.; Ferguson, K.M.; Verkleij, A.J.; van Dongen, G.A.; van Bergen en Henegouwen, P.M. A biparatopic anti-EGFR nanobody efficiently inhibits solid tumour growth. Int. J. Cancer 2011, 129, 2013-2024. [CrossRef]

27. Vosjan, M.J.; Perk, L.R.; Roovers, R.C.; Visser, G.W.; Stigter-van Walsum, M.; van Bergen En Henegouwen, P.M.; van Dongen, G.A. Facile labelling of an anti-epidermal growth factor receptor Nanobody with 68Ga via a novel bifunctional desferal chelate for immuno-PET. Eur. J. Nucl. Med. Mol. Imaging 2011, 38, 753-763. [CrossRef]

28. Beltran Hernandez, I.; Rompen, R.; Rossin, R.; Xenaki, K.T.; Katrukha, E.A.; Nicolay, K.; van Bergen En Henegouwen, P.; Grull, H.; Oliveira, S. Imaging of Tumor Spheroids, Dual-Isotope SPECT, and Autoradiographic Analysis to Assess the Tumor Uptake and Distribution of Different Nanobodies. Mol. Imaging Biol. 2019, 21, 1079-1088. [CrossRef]

29. van Driel, P.; Boonstra, M.C.; Slooter, M.D.; Heukers, R.; Stammes, M.A.; Snoeks, T.J.A.; de Bruijn, H.S.; van Diest, P.J.; Vahrmeijer, A.L.; van Bergen En Henegouwen, P.M.P.; et al. EGFR targeted nanobody-photosensitizer conjugates for photodynamic therapy in a pre-clinical model of head and neck cancer. J. Control. Release 2016, 229, 93-105. [CrossRef]

30. van Lith, S.A.M.; van den Brand, D.; Wallbrecher, R.; Wubbeke, L.; van Duijnhoven, S.M.J.; Makinen, P.I.; Hoogstad-van Evert, J.S.; Massuger, L.; Yla-Herttuala, S.; Brock, R.; et al. The effect of subcellular localization on the efficiency of EGFR-targeted VHH photosensitizer conjugates. Eur. J. Pharm. Biopharm. 2018, 124, 63-72. [CrossRef]

31. de Bruijn, H.S.; Mashayekhi, V.; Schreurs, T.J.L.; van Driel, P.; Strijkers, G.J.; van Diest, P.J.; Lowik, C.; Seynhaeve, A.L.B.; Hagen, T.; Prompers, J.J.; et al. Acute cellular and vascular responses to photodynamic therapy using EGFR-targeted nanobody-photosensitizer conjugates studied with intravital optical imaging and magnetic resonance imaging. Theranostics 2020, 10, 2436-2452. [CrossRef] [PubMed]

32. Driehuis, E.; Spelier, S.; Beltran Hernandez, I.; de Bree, R.; Stefan, M.W.; Clevers, H.; Oliveira, S. Patient-Derived Head and Neck Cancer Organoids Recapitulate EGFR Expression Levels of Respective Tissues and Are Responsive to EGFR-Targeted Photodynamic Therapy. J. Clin. Med. 2019, 8, 1880. [CrossRef] [PubMed]

33. Oliveira, B.L.; Guo, Z.; Bernardes, G.J.L. Inverse electron demand Diels-Alder reactions in chemical biology. Chem. Soc. Rev. 2017, 46, 4895-4950. [CrossRef] [PubMed] 
34. Mitsunaga, M.; Ogawa, M.; Kosaka, N.; Rosenblum, L.T.; Choyke, P.L.; Kobayashi, H. Cancer cell-selective in vivo near infrared photoimmunotherapy targeting specific membrane molecules. Nat. Med. 2011, 17, 1685-1691. [CrossRef] [PubMed]

35. Lee, M.D.; Tong, W.Y.; Nebl, T.; Pearce, L.A.; Pham, T.M.; Golbaz-Hagh, A.; Puttick, S.; Rose, S.; Adams, T.E.; Williams, C.C. Dual Site-Specific Labeling of an Antibody Fragment through Sortase A and pi-Clamp Conjugation. Bioconj. Chem. 2019, 30, $2539-2543$. [CrossRef] [PubMed]

36. AlQahtani, A.D.; O'Connor, D.; Domling, A.; Goda, S.K. Strategies for the production of long-acting therapeutics and efficient drug delivery for cancer treatment. Biomed. Pharmacother. 2019, 113, 108750. [CrossRef]

37. Johnson, J.M.; Cognetti, D.M.; Curry, J.M.; Mott, F.E.; Kochuparambil, S.T.; McDonald, D.R.; Fidler, M.J.; Vasan, N.R.; Razaq, M.A.; Tahara, M.; et al. Integrated data review evaluating safety, pharmacokinetics (PK) and immunogenicity of RM-1929 photoimmunotherapy (PIT) in subjects with locoregional, recurrent head and neck squamous cell carcinoma (rHNSCC). Ann. Oncol. 2019, 30, 462. [CrossRef]

38. Bui, J.D.; Suslov, N.; Yadav, D.; Fong, J.; Sun, E.; Haedo, M.; Garcia-Guzman, M. Intratumoral and peripheral exploratory biomarker analysis in patients with locoregional, recurrent head and neck squamous cell carcinoma (rHNSCC) treated with RM-1929 photoimmunotherapy. Ann. Oncol. 2019, 30, v470. [CrossRef]

39. Cognetti, D.M.; Johnson, J.M.; Curry, J.M.; Mott, F.; Kochuparambil, S.T.; McDonald, D.; Fidler, M.J.; Stenson, K.; Vasan, N.R.; Razaq, M.; et al. Results of a phase 2a, multicenter, open-label, study of RM-1929 photoimmunotherapy (PIT) in patients with locoregional, recurrent head and neck squamous cell carcinoma (rHNSCC). J. Clin. Oncol. 2019, 37. [CrossRef]

40. Tintelnot, J.; Baum, N.; Schultheiss, C.; Braig, F.; Trentmann, M.; Finter, J.; Fumey, W.; Bannas, P.; Fehse, B.; Riecken, K.; et al. Nanobody Targeting of Epidermal Growth Factor Receptor (EGFR) Ectodomain Variants Overcomes Resistance to Therapeutic EGFR Antibodies. Mol. Cancer Ther. 2019, 18, 823-833. [CrossRef]

41. Spring, B.Q.; Rizvi, I.; Xu, N.; Hasan, T. The role of photodynamic therapy in overcoming cancer drug resistance. Photochem. Photobiol. Sci. 2015, 14, 1476-1491. [CrossRef] [PubMed]

42. van Lith, S.A.M.; van den Brand, D.; Wallbrecher, R.; van Duijnhoven, S.M.J.; Brock, R.; Leenders, W.P.J. A Conjugate of an Anti-Epidermal Growth Factor Receptor (EGFR) VHH and a Cell-Penetrating Peptide Drives Receptor Internalization and Blocks EGFR Activation. Chembiochem 2017, 18, 2390-2394. [CrossRef] [PubMed]

43. Merlino, G.T.; Xu, Y.H.; Ishii, S.; Clark, A.J.; Semba, K.; Toyoshima, K.; Yamamoto, T.; Pastan, I. Amplification and enhanced expression of the epidermal growth factor receptor gene in A431 human carcinoma cells. Science 1984, 224, 417-419. [CrossRef] [PubMed]

44. de Boer, E.; Warram, J.M.; Hartmans, E.; Bremer, P.J.; Bijl, B.; Crane, L.M.; Nagengast, W.B.; Rosenthal, E.L.; van Dam, G.M. A standardized light-emitting diode device for photoimmunotherapy. J. Nucl. Med. 2014, 55, 1893-1898. [CrossRef] [PubMed] 